\title{
On The Impact Of State And Local Government Policies On Human Migration: A Log-Linear Analysis
}

\author{
RichaRd J. Cebula*
}

\section{INTRODUCTION}

Government policies influence society in a wide variety of ways through taxation, transfer, and expenditure activities. As taxation, transfers, and expenditures are carried out, income redistribution and variations in the levels of burdens and benefits from governmental action are experienced. For example, when a governmental unit increases the level of welfare benefits, it further redistributes income through a taxation-transfer process. Alternatively whenever a governmental unit raises the levels of, say, educational spending and of taxes, there will likely result a myriad of additional benefits and costs for the various members of the society.

The objective of this paper is to investigate the impact on human migration (locational decisions) of state and local government expenditure and income redistribution policies. Tiebout [8, p. 418] has suggested that the "... consumer-voter may be viewed as picking that community which best satisfies his preference pattern for public goods." Presumably, "... the consumer-voter moves to that community whose local government best satisfies his set of preferences." [8, p. 418] This paper seeks to test the validity of this argument by focusing on the migration impact of two types of state and local government spending policies: the average level (per recipient) of welfare payments and per capita non-welfare public expenditures.

To carry out the analysis, attention will be focused upon two types of migrants: white migrants and black migrants. A much larger proportion of blacks than of whites is eligible for welfare benefits. Thus, it may be expected that the level of welfare benefits will act as a stronger attraction to black would-be migrants than to their white counterparts. In addition, by virtue of the fact that welfare benefits represent a redistribution of income from the economically better-off to the economically worse-off, whites may tend to view areas with higher welfare benefits as areas which on average redistribute income from themselves to others. Thus, ceteris paribus, the would-be white migrants may be expected to gravitate to areas with lower levels of welfare benefits. The present paper in part investigates whether in fact welfare benefits tend to have

*Dept. of Economics, Emory University, Atlanta, Georgia 30322. 
these opposing effects on white and black migrants. This will be referred to as hypothesis "A".

On the other hand, the higher the per capita level of combined state and local government non-welfare spending, presumably the higher the level of general benefits per capita which are derived from such spending. In turn, the higher the level of such spending in an area, the more attractive the area will tend to be to would-be migrants, black and white. However, to the extent that (a) higher per capita state-local government expenditure levels imply higher levels of local tax burdens per capita and (b) whites view their share of the tax burden as relatively greater per capita than that of blacks, higher levels of per capita local government spending may be expected to be more potent an attracting influence on black migrants than on white migrants. In point of fact, higher levels of per capita non-welfare public spending may even act as a net deterrent to white migrants. The present paper in part, then, seeks to investigate whether in fact the level of per capita local government spending is a more potent positive attraction to black migrants than to white migrants. This is referred to as hypothesis " $\mathrm{B}$ ".

Section I below sets out the basic migration model of this paper. This model includes variables to enable us to test hypotheses " $A$ " and " $B$ " above. For completeness, the model includes three additional variables: income levels, unemployment rates, and air pollution rates. General empirical results are offered in Section II, while basic conclusions are provided in Section III.

\section{THE MIGRATION MODEL}

To determine the validity of hypotheses " $\mathrm{A}$ " and " $\mathrm{B}$ ", the following model of net migration is postulated:

$$
\mathrm{Mi}=\mathrm{Mi}(\mathrm{Yi}, \mathrm{Ui}, \mathrm{Wi}, \mathrm{Ei}, \mathrm{Pi}),
$$

where $M i$ is a measure of net migration (in-migration less out-migration) to area $i, Y i$ is a measure of the per capita income level in area $i, U i$ is the unemployment rate in area $i, W i$ is a measure of average welfare benefits in area $i, E i$ represents per capita local and state government non-welfare expenditures in area $i$, and $P i$ is a measure of the level of air pollution in area $i$.

The variable $M i$ is used to measure migration of whites on the one hand and of blacks on the other. $M i$ is defined then as the ratio of the net migration of whites or blacks to state $i$ between 1960 and 1970 to the total population of state $i$ in 1960. Mi is formulated thusly so as to control for variations in the population among the states considered. The migration data were obtained for 48 states (Alaska and Hawaii were excluded from study) from the Statistical Abstract of the United States, 1973 [13, Table 29] and from the Statistical Abstract of the United States, 1968 [12, Table 28]. 
The variable $Y i$ refers to the per capita personal income level of whites or blacks for the year 1960. These data were obtained from the 1960 Census of the Population [9, Table 67]. In accord with conventional economic theory, it is assumed that white and black migration should each be directly related to white and black income, respectively, so that

$$
\frac{\partial \mathrm{Mi}}{\partial \mathrm{Yi}}>0 .
$$

The variable $U i$ measures the unemployment rate for whites on the one hand and for blacks on the other hand. The variable $U i$ was obtained by averaging the 1960 and 1970 unemployment rates for whites and for blacks. The data were obtained from the 1960 Census of the Population [9, Table 115] and the 1970 Census of the Population [10, Table 115]. The expected relationship between migration (white or black) and the unemployment rate is

$$
\frac{\partial \mathrm{Mi}}{\partial \mathrm{Ui}}<0 .
$$

The reasoning here is quite simple. In particular, for those whose movement between states is not of the job transfer variety, the higher the unemployment rate in a state, the greater the uncertainty (risk) associated with obtaining employment in that state. ${ }^{1}$

To measure welfare benefits, $W i$, data on monthly payments in the year 1971 to welfare recipients in the form of aid to dependent children by state were gathered. The data source was the Statistical Abstract of the United States, 1973 [13, Table 490]. Since our proxy for welfare benefits effectively may represent a form of benefit (i.e., income) for those eligible for such payments, the following relationship may be expected:

$$
\frac{\partial \mathrm{Mi}}{\partial \mathrm{Wi}}>0 .
$$

In accord with our introductory comments, however, we would expect blacks to be differentially responsive to welfare benefits than whites. In particular, since a larger proportion of blacks are eligible for welfare benefits, blacks can be expected to be more attracted by welfare benefits than whites. In addition, since whites may view higher welfare benefits in an area as implying a higher degree of unfavorable net income redistribution, they can be expected to be less attracted to areas with higher welfare benefits than blacks. In fact, it is entirely possible that, ceteris paribus, they may prefer to move to areas with lower welfare benefits;

1See, for example, Cebula [1]. 
thus, while blacks may be argued to conform to (4), for whites it may be that

$$
\frac{\partial \mathrm{Mi}}{\partial \mathrm{Wi}}<0 .
$$

To measure $E i$, data were assembled from the Statistical Abstract of the United States, 1973 [13, Table 662] on total (non-welfare) direct per capita expenditures of state and local governments in 1970. These expenditures included spending for education, highways, and health and hospitals. In accord with our introductory remarks, $E i$ presumably may represent, for blacks, a form of benefit, so that the higher the level of $E i$ in a state, the more attractive residence in that state. Thus, for blacks it is hypothesized that

$$
\frac{\partial \mathrm{Mi}}{\partial \mathrm{Ei}}>0 .
$$

The impact of $E i$ on white migration may not be so clear-cut, however. As argued above, while higher levels of $E i$ may imply greater benefits for whites, they may also imply higher levels of local taxation and on average an increased degree of unfavorable income redistribution. Thus, the relationship between $M i$ for whites and the variable $E i$ is not a priori determinate:

$$
\frac{\partial \mathrm{Mi}}{\partial \mathrm{Ei}}=0 .
$$

To measure air pollution, $P i$, data were assembled measuring suspended particulate matter ${ }^{2}$ by state for the year 1966 . The data were obtained from the Statistical Abstract of the United States, 1968 [12, Table 262]. Presumably, higher pollution rates impose greater disutility on individuals in terms of general health and discomfort than do lower pollution rates, ceteris paribus. Thus, the following relationship would be expected for both whites and blacks:

$$
\frac{\partial \mathrm{Mi}}{\partial \mathrm{Pi}}<0 .
$$

\section{EMPIRICAL RESULTS}

Conceptually, what is proposed is the estimation for white migration and for black migration of log-linear regression equations of the form

$$
\begin{aligned}
& \log \mathrm{Mi}=\log \mathrm{a}+\mathrm{b} \log \mathrm{Yi}+\mathrm{c} \log \mathrm{Ui} \\
& +\mathrm{d} \log \mathrm{Wi}+\mathrm{e} \log \mathrm{Ei}+\mathrm{f} \log \mathrm{Pi}+\mathrm{u},
\end{aligned}
$$

2This consists of micrograms per cubic meter of air of particles of smoke, dust and fumes and droplets of viscous liquid remaining in the air for varying periods of time. 
where $a$ is a constant and $u$ is a random error term.

The regression results for white migration and for black migration are given in equations (8) and (9), respectively:

$$
\begin{aligned}
& \log \mathrm{Mi}=-0.75953+\underset{(3.3082)}{0.34686} \log \mathrm{Yi}-\underset{(0.7576)}{0.04180} \log \mathrm{Ui} \\
& \text { - } 0.12585 \log \mathrm{Wi}-0.01661 \log \mathrm{Ei}-0.06823 \log \mathrm{Pi} \text {, } \\
& \text { (2.8827) (0.1378) } \\
& \text { (1.6827) } \\
& \mathrm{DF}=42, \mathrm{R}^{2}=.5431 \\
& \log \mathrm{Mi}=-2.04582+\underset{(0.0424)}{0.00528} \log \mathrm{Yi}-\underset{(1.1302)}{0.11868} \log \mathrm{Ui} \\
& +0.29580 \log \mathrm{Wi}+0.54669 \log \mathrm{Ei}-0.00661 \log \mathrm{Pi} \text {, } \\
& \text { (2.4881) } \\
& \text { (2.3741) } \\
& \text { (0.0714) } \\
& \mathrm{DF}=42, \mathrm{R}^{2}=.6772,
\end{aligned}
$$

where the terms in parentheses are t-values.

We first analyze the regression results for white migration (8). The income variable worked as hypothesized and was statistically significant at the one percent level. This conforms to the "conventional wisdom". The unemployment variable had the hypothesized sign but was not statistically significant at even the ten percent level. The welfare variable showed up with a negative coefficient and was statistically significant at the one percent level. This confirms the hypothesis in $(4 \mathrm{~A})$ that whites view a higher welfare level as implying on average a more unfavorable net income redistribution. Thus, they tend to gravitate to states where the welfare benefits per capita are lower, ceteris paribus. The expenditure variable, $E i$, turned up with a negative coefficient, but was not statistically significant at even the ten percent level. The possibility of a negative coefficient was indicated by (5B) above, where it was suggested that whites on average may view a higher level of $E i$ not only as implying higher benefits from the public sector but higher taxation and a higher degree of unfavorable income redistribution as well. Finally, the pollution variable showed up with the hypothesized sign and was statistically significant at the five percent level. Apparently, white migrants prefer lower pollution rates to higher pollution rates, ceteris paribus. The statistical significance for $P i$ is contrary to an earlier study of migration between metropolitan areas in the United States for the 1960-1968 period (see Cebula and Vedder [2]).

We next interpret the regression results on black migration (9). The income variable here had the hypothesized sign but was not statistically significant at even the ten percent level. This apparent insensitivity of migrants to wage differentials has been found elsewhere (see Cebula [1], Chapin, Vedder and Gallaway [3], Gallaway and Cebula [4]) but has been shown to be compatible with conventional theory under certain 
conditions (see Cebula and Vedder [2] and Gatons and Cebula [6]). The unemployment variable $U i$ had the hypothesized sign but, as in the case of white migration, this variable was not statistically significant at the ten percent level. The welfare variable $W i$ here had the hypothesized sign (see (4)) and was statistically significant at the one percent level. This is in sharp contrast to the results on white migration (8). Next, as hypothesized in (5A), the public expenditure variable $E i$ had a positive coefficient. In addition, $E i$ was a statistically significant determinant of black interstate net migration. Thus, the level of public non-welfare expenditures as a proxy for public benefits apparently acts as a potent lure to black migrants. Finally, although the pollution variable $P i$ had the expected sign, it was not significant at even the ten percent level. This is in contrast to the results in (8) on white migration but is consistent with another recent study by Cebula and Vedder [2].

\section{CONCLUSIONS}

We now comment as to the validity of hypotheses "A" and "B". As formulated in the Introduction of this paper and summarized in equations (4) and (4A), hypothesis "A" argues that white migrants and black migrants will have opposing reactions to the level of welfare benefits in an area, i.e., whites will be attracted to areas with lower welfare benefits and blacks to areas with higher welfare benefits. As equations (8) and (9) and the discussions thereof indicate, the interstate migration patterns of whites and blacks support hypothesis "A". One may thus infer that state-local income redistribution policies may be significant determinants of human migration, with higher levels of welfare deterring whites and attracting blacks.

As our Introduction and equations (5A) and (5B) indicate hypothesis "B" holds that blacks seeking benefits will be attracted to areas of higher per capita (non-welfare) public expenditures whereas whites, because higher per capita public expenditures imply higher taxation and a greater average degree of unfavorable net income redistribution, may be expected to be less responsive to, and perhaps even deterred by, higher per capita public (non-welfare) spending. Regression result (9) clearly lends support to hypothesis "B", with blacks being attracted to areas with higher public (non-welfare) expenditure. Regression result (9) indicates that the level of public (non-welfare) spending was not a potent net influence on white migrants. This is consistent with hypothesis " $\mathrm{B}$ " as formulated in part by $(5 \mathrm{~B})$.

In closing, we thus conclude that, as Tiebout [8] had suggested might occur, state-local public policies have apparently had a significant effect on the interstate allocation of human resources in the United States.

REFERENCES

1. R. J. Cebula, "Labor Migration and the Cost of Living," Review of Regional Studies, Fall, 1973, 3, 121-124.

2. R. J. Cebula and R. K. Vedder, "A Note on Migration, Economic Opportunity and the Quality of Life," Journal of Regional 
Science, August, 1973, 13, 205-211.

3. G. L. Chapin, R. K. Vedder, and L. E. Gallaway, "The Determinants of Emigration to South Africa, 1950-1967," South African Journal of Economics, December, $1970,38,374-381$.

4. L. E. Gallway and R. J. Cebula, "Differentials and Indeterminacy in Wage Rate Analysis: An Empirical Note," Industrial and Labor Relations Review, April, 1973, 26, 991-995.

5. L. E. Gallway, R. F. Gilbert and P. E. Smith, "The Economics of Labor Mobility:
An Empirical Analysis," Western Economic Journal, June, 1967, 5, 211-223.

6. P. K. Gatons and R. J. Cebula, "Wage Rate Analysis: Differentials and Indeterminacy," Industrial and Labor Relations Review, January, 1972, 25, 207-212.

7. L. A. Sjaastad, "The Costs and Returns of Human Migration," Journal of Political Economy, October, 1962, Supplement, 70, 80-93.

8. C. M. Tiebout, "A Pure Theory of Local Expenditures," Journal of Political Economy, October, 1956, 64, 416-424. 